\title{
CORPORATE SOCIAL RESPONSIBILITY AND PROFESSIONAL TRAINING FOR IMMIGRANT: THE BUSINESS CASE
}

\author{
Dario A. Schirone ${ }^{2}$ and Germano Torkan \\ University of Bari, \\ Department for the Study of Mediterranean Societies, Bari, Italy.
}

\begin{abstract}
:
Corporate social responsibility represents for IKEA a competitive factor of extraordinary importance. Social policies of racial integration are one of the challenges that the Swedish multinational faces day to day. In the present work it stands out as the racial integration is not only a socially desirable goal; the economic utility of a multi-ethnic integration policy is also highlighted, because of changes occurred in the ethnic composition of customers.
\end{abstract}

\section{KEYWORDS:}

Corporate social responsibility; placement; immigration.

\section{INTRODUCTION}

Growth is considered sustainable "if it meets the needs of present generations without compromising the ability of future generations to meet their own needs" (WCED, 1987). The introduction of a common definition of sustainable development should meet the need for solving the problems related to the preservation of eco-sustainability of our planet. Truly, the definition abovementioned does not refer explicitly to the environment, as the level of inter-generational and intra-generational welfare of the community; this aim cannot be achieved and maintained without using efficiently any of the scarce resources available.

Economics, for a long time, deal with the efficient allocation of scarce resources, but only recently have tried to combine this objective with environmental sustainability. Moreover, there is no possibility to achieve a satisfactory level of welfare without respecting the fundamental rights of individuals. Sustainable development is achievable taking into account extra-economic variables, including the right to health and education, the guarantee to live in healthy environments, in which respects the cultural and natural heritage.

This work is the result of joint reflection of the two authors; however, it is possible to attribute chapters 1 and 2 to Germano Torkan and chapters 3, 4 and 5 to Dario A. Schirone

${ }^{2}$ Corresponding author: Email address: darioschirone@libero.it

DOI : 10.5121/ijmit.2012.4402 
International Journal of Managing Information Technology (IJMIT) Vol.4, No.4, November 2012

Whereas companies, as open systems, have exchanges of matter, energy and information with environment, the present work wants to demonstrate that the Swedish multinational IKEA (the world leader furnishings company), having identified sustainable development as a value business, has adopted socially responsible conduct also towards new immigrant households. The interest in this group of individuals was born certainly because of the significant increase of the number of these immigrants on the Italian territory; therefore IKEA has elaborated a strategy to non-EU citizens, promoting and fulfilling social and economic purposes.

\section{ENVIRONMENTAL ECONOMICS AND BUSINESS STRATEGY}

In the 60's the question of environmental degradation began to raise and in the 70's, as a result of the energy crisis, there was a review of the relationship between man and nature, identifying the first not as a ruler of the second, but as an exploiter, who does not care for future generations (Martucci, Schirone, 2011).

In the theoretical debate two interpretations were born: the first was the neo-Malthusian interpretation that, denying the possibility of long-term development, proposed that the economic systems could be kept in a steady state, reducing the productive activity (Meadows et al., 1972); the second perspective stated that the Malthusian scarcity was surmountable by the substitution of resources and through technological progress. Therefore it would be possible to support the development in the long run, thanks to efficient market mechanisms (Simon-Kahn, 1984).

Thus it began to outline the theoretical substrate of environmental economics which is divided into different expressions, some of them more extreme, others more moderate and technocratic. In other words, the free action of market forces contrasts with the existence of environmental constraints. The first replaces scarce and economically inconvenient resources with other resources that can guarantee sustainable development; while the constraints are an expected interruption of the process of economic growth and an obstacle to the increasing of productivity.

In 1987 Brundtland Report defined the sustainable development, showing that environmental protection and development are inextricably linked; this assumption was justified because if there is poverty and, therefore, there is no development, the environment deteriorates and conversely in a degraded environment poverty develops. The development is no longer part of the environmental problem, but it is one of the solutions. (Nespor, 2009).

Sustainable development is achievable through the substitution of capital produced with natural resources in order to allow the construction of a new production paradigm, the entrepreneur uses to derive the greatest possible benefit. As a scarce resource is more expensive than an available one, the replacement of the first with the second, allows to provide a more efficient combination. In this case of substitution of natural resources with capital produced, the level of economic activity would remain constant, without reducing the availability of resources for future generations.

Ecologists, instead, believe that natural resources and capital produced are not substitutable , but they are complementary, since each higher level of well-being is associated with a greater amount of resources. 
International Journal of Managing Information Technology (IJMIT) Vol.4, No.4, November 2012

Moreover, it is evident that the consistency of the combination of natural resources /capital produced can be maintained only through their reintegration, both being subject to degradation. Consequently it is believed that the level of development and environmental impact are inversely proportional. In fact, if disposable income per capita increases, so the consumption grows at a lower rate or, at least, is constant, while the disutility of environmental degradation increases. "As incomes rise, the demand for improvements in environmental quality will increase, as will the resources available for investment" (World Economic Report., 1992, p. 39).

In other words, "there is clear evidence that, although economic growth usually leads to environmental degradation in the early stages of the process, in the end the best - and probably the only - way to attain a decent environment in most countries is to become rich "(Beckerman, 1992).

This happens only if, with the increase of production scale, technological progress allows a reduction of the quantity of inputs used and promotes the adoption of production processes with lower emissions of harmful substances to the environment. It looks relevant the role of business in making possible sustainable development and especially its relationship with the environment. Every company should adopt strategies that enable efficient productions in terms of emission of harmful substances: this must be true both in the usage of energy and raw materials, as well as in the waste production.

The eco-efficiency of the company can be improved using tools such as the analysis of the life cycle of the product and environmental management systems (ISO 14000 and EMAS). In order to achieve sustainable development, it is necessary to pursue a positive economic result while protecting the environment: on the one hand, this is a cost for the company, on the other it assures many opportunities related to its ability to innovate. "Some companies, dealing with problems related to climate change, discover new opportunities to improve or extend their competitive position, creating new products (such as hybrid cars) that meet demands arising from environmental problems, driving a sectorial restructuring aimed at more effectively addressing climate issues, or innovating activities affected by climate change in order to gain a true competitive advantage "(Porter-Reihardt, 2007).

Relying on chain of value, the company evaluates the environmental impact of its internal and external activities and reducing it can benefit not only introducing innovations in both product and process, but also adopting marketing strategies aimed at sustainability; for example, practicing lower prices for recycled products and / or discounts for the withdrawal of the ones used, use of packaging.

At the same time companies are also referred to deal with a changing social scenario. A comprehensive economic analysis of business performance cannot be separated from an approach which takes into account the inter-temporal connections of human choices, as well as social interactions among stakeholders who face in the competitive business (Airoldi, Brunetti, Coda, 2005).

It is therefore necessary to establish a business planning to enable the enhancement of human capital, in its two major components: social capital and personal capital (Adler, Kwon, 2002). 
International Journal of Managing Information Technology (IJMIT) Vol.4, No.4, November 2012

\section{IKEA: EXAMPLE OF A BUSINESS STRATEGY AIMED AT SUSTAINABILITY}

IKEA, a leading company in furniture ${ }^{3}$, has implemented sustainability for corporate purposes, making component of social and environmental factors constantly present in the business process (with employees, suppliers, etc.).

In the early 90's, IKEA took its first steps towards sustainability, "looking back to its vision and actions from a social and environmental perspective. Changes that have been introduced have gone through all the functions of IKEA's supply chain, from design to logistics, from retail to the relationship with suppliers" (Bussolo by 2009, Social Environment Report).

The protection of the environment through the reduction of harmful emissions is carried out by IKEA using within its stores energy saving light bulbs that reduce the emission of $\mathrm{CO} 2$ or selling refrigerators HFC Free.

Since 2007, in order to reduce direct emissions of CO2, IKEA has formalized its commitment through the international project "IKEA goes renewable" by procuring energy from renewable sources (since 2004 it has been supplying shops with electricity produced from hydroelectric plants in Valle d 'Aosta).

In 2000 the standard IWAY (IKEA Way of Purchasing Home Furnishing)was born; it was designed to identify 80 minimum social and environmental factors suppliers and subcontractors must possess in order to become partners of the Swedish company.

Suppliers and subcontractors of services, transport and production must comply with this code of conduct $^{4}$. It imposes:

- Conditions of safety such as fire prevention procedures, systems for accident prevention guards, light and suitable temperatures in the workplace;

- Minimum wage;

- Absolute ban on overtime illegal;

- Rejection of child labor.

Compliance with the code of conduct shall be verified by audit, carried out by technicians from IKEA or by external companies (including KPMG and Price WaterhouseCoopers) ${ }^{5}$

IKEA does not overlook the training of its employees, especially those who have direct contact with their customers: it is an education concerning social and environmental issues.

Employees play a central role for the corporate business, it will be necessary, therefore, to achieve a good level of personnel satisfaction by providing a healthy, informal and opened environment to guarantee a proper physical, mental and social development.

\footnotetext{
${ }^{3}$ For IKEA Europe represents the largest market segment, which accounts for $79 \%$ of sales, followed by
} North America with $15 \%$ and Asia with $6 \%$. 
International Journal of Managing Information Technology (IJMIT) Vol.4, No.4, November 2012

Creating a positive atmosphere inspired by the principles of pro-sociality and respect for diversity realizes the integration between social responsibility and responsiveness, and the development of plans and programs social-oriented (Wartick, Cochran, 1985; Clarkson, 1995).

This kind of approach determines, thus, several orders of consequences:

- Within the company, a fertile climate of mutual respect and safety for workers is created, representing a socially desirable outcome;

- Outdoors, the company is perceived positively by consumers, creating an unusual surplus presumably accounted under the heading "Promotion and communication."

- The encouragement of a spirit of cooperation towards the organization;

- The guarantee of a result qualitatively appreciable, showing a "link between social performance and financial performance" (D'Orazio, 2004).

\section{The PRofessional Training OF IMMigrants, SOCIAL AND ECONOMIC ASPECTS}

In the strategy of the Swedish multinational customer satisfaction through a qualitative shopping experience in the store occupies a key role . Consequently a relevant position in the purchasing process is taken by the staff, especially by those who have a contract of indefinite duration with IKEA.

The $85 \%$ of the workforce is employed on permanent contracts and only $15 \%$ have a fixed-term contract (Report, Social Environment 2011).

In order to create an informal and open to discussion environment is necessary to promote "diversity" as a business value.

For IKEA enhancing the diversity is not an empty slogan, but a practice valuable declined in different ways:

\footnotetext{
${ }^{4}$ The code of conduct on child labor and on the purchase of food is inspired by the basic principles of labor legislation and the contents of the ILO Declaration (International Labour Organization), of the Conference of Rio de Janeiro on Environment and Sustainable Development and the UN Declaration on Human Rights.

${ }^{5}$ The check on suppliers are performed every two years and in 2009, in Southern Europe, the compliance rate recorded was $98.4 \%$ ( Report, 2009).Still in fiscal year 2009, the protocol was expanded following the international agenda on atmospheric warming. The minimum requirements to become an IKEA partner have become more rigid, by adopting energy reduction plan, ie a plan for environmental improvement, with concrete and measurable goals based on controls on the origin of wood.
} 
International Journal of Managing Information Technology (IJMIT) Vol.4, No.4, November 2012

- Age. The contribution of all employees is fundamental and is independent of age or length of service. Truly the $12.22 \%$ are over 45 years old, $4.77 \%$ more than 25 years, $39.24 \%$ are aged between 25 and 34, and $43.77 \%$ aged between 35 and 44 years.

- Gender differences. The quotas for women account for $58 \%$ of the personnel of the base, while the number of women at managerial level is around $41 \%$.

- Geographical origin. Although Italians are the $94 \%$ of the workforce, the contribution of different cultures is much appreciated and mobility between stores all over the world is encouraged and promoted through the company intranet.

Convinced of the importance to be reserved for social issues, IKEA in 2011 has set a process of work placement for a group of immigrants from different regions of Africa (Morocco, Nigeria, Senegal) in its store in Rome. IKEA has received young people indicated by Caritas of Rome, guests at their facilities and in precarious living conditions. In most cases they were refugees, immigrants without families, who were offered the chance of a paid formative training for several months. Each of them has been supported throughout the training period by a tutor, who monitored the axes of progress. The formation was monitored by intermediate follow-up by the head of department. In this way tools to qualify in the labor market have been offered them and they have received the necessary skills to be absorbed on the staff of applicant companies. It was a professional and educative experience, so that for some of them a working proposal recruitment has come.

In 2011, this project has involved 14 people, but the company plans to extend the project throughout the country foreseeing to activate more than 200 trainings to be carried out in 20 Italian stores. To the sensitivity towards social is added an economic strategy: increase the share of immigrant customers.

For better understanding this objective, it is necessary to analyze the IKEA's customer profile and check what impact non-EU citizens have on the business (or may have in the long term).Getting to specifics, we note that $57 \%$ of customers are female (Figure 1), and more than $60 \%$ have an 'age between 25 and 50 years (Table 1).

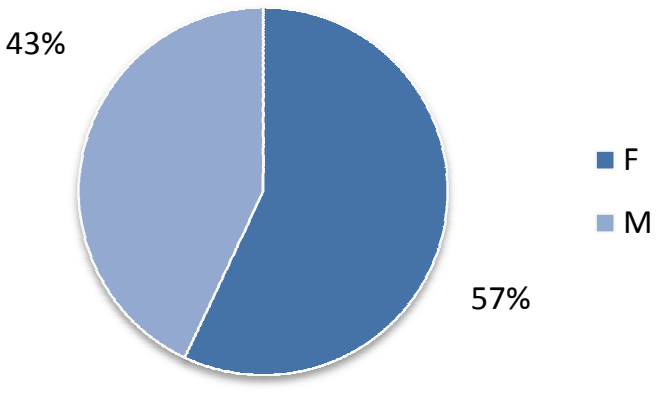

Fig.1: Gender breakdown of customers 
International Journal of Managing Information Technology (IJMIT) Vol.4, No.4, November 2012

Tab. 1: Age of customers

\begin{tabular}{|c|c|}
\hline $18-24$ years & $19 \%$ \\
\hline $25-34$ years & $28 \%$ \\
\hline $35-49$ years & $35 \%$ \\
\hline $50-59$ years & $12 \%$ \\
\hline $60+$ years & $6 \%$ \\
\hline
\end{tabular}

The average level of education is high, in fact, about $50 \%$ have a bachelor's degree (Figure 2).

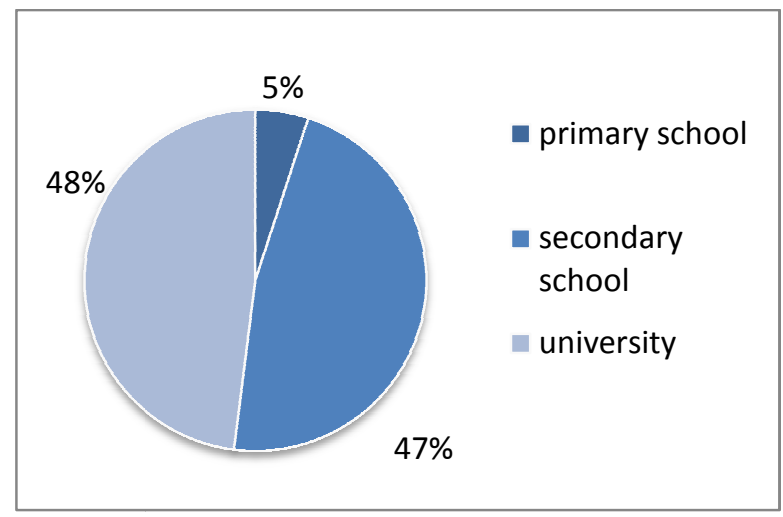

Fig.2: Level of education

Almost all of the customers are Italian or EU, as the number of visitors and customers outside the EU is growing ; infact, $91 \%$ of the clients are Italian or EU, and only $9 \%$ are immigrants (IKEA, Customer Satisfaction Index 2011).

\section{CONCLUSIONS}

While not representing yet a significant target, the number of immigrants is growing. in fact it increased from $6 \%$ in 2009 to $8 \%$ in 2010 , in line with the national trend.

The number of families has increased rapidly mainly due to the increase in the number of divorces, but especially for the increasing number of immigrants (an increase of ' $11.8 \%$ in 2009 compared to 2008). In 2009, strangers are 3.9 million, i.e. $7 \%$ of the population $(+2.5 \%$ compared to 2005, ISTAT 2010).

Most of them live in the North (62\%), especially in Turin, Milan and Brescia (Annual Demographic national ISTAT 2010). 
International Journal of Managing Information Technology (IJMIT) Vol.4, No.4, November 2012

The increased presence of immigrants has certainly contributed to the company's turnover; for Italy turnover in the fiscal year 2011 amounted to 1,640 million euro, an increase of $6.5 \%$ compared to fiscal year 2010.

The fact that IKEA shall integrate its staff (although minimally) with multiethnic personnel it is direct consequence of the multinational social orientation, which aims to use the differences as an opportunity for personal and professional growth, but it is also likely that meets or may satisfy an economic interest. Multiethnic staff promotes the image of a company close to the needs of a consumer born in distant countries who can find in IKEA an opening to different cultures, or simply an atmosphere in which the "colors" are offered not only by the décor, but also by the heterogeneity of the staff.

Sustainability is no longer a simple environmental and social promotion; it becomes a business strategy when it is absorbed as a turning point for the company. Racial integration within IKEA is not, therefore, a simple choice of image, but it becomes functional to an economic project capable of self-sustaining in the long term.

\section{Bibliography:}

[1] Adler P.S., Kwon S. 2002. Social capital: Prospects for a New Concept. Academy of Management Review, 27:17-40.

[2] Airoldi G., Brunetti G., Coda V. 2005. Corso di economia aziendale. Bologna: il Mulino.

[3] Becattini G. 1983. Principi di Economia Politica. UTET: Torino.

[4] Beckerman W. 1992. Economic growth and the environment: whose growth? Whose environment?. World Development, No. 20 pp. 481-496.

[5] Capecchi V. 2005. La responsabilità sociale dell'impresa. Carocci, Roma Fontana.

[6] CISL Centro studi industria leggera 2009. La distribuzione del mobile nelle province Italiane. Milano.

[7] Clarkson M.B.E. 1995. A stakeholder Framework for analyzing and evaluating corporate social performances. Academy of Management Review, 20 (1): 92-117.

[8] D’Orazio E. 2004. Gestione degli stakeholders, assets intangibili e leadership etica. Business Ethics and Corporate Social Responsibility in a Global Economy. Milano: Notizie di Politeia, 74, pp. 87108.

[9] IKEA 2000. The Ikea Way of Purchasing Home Furnishing.

[10] IKEA 2010. www.ikea.com.

[11] IKEA 2009. Verso la sostenibilità, Report ambientale, sociale, risorse umane.

[12] IKEA 2010. Verso la sostenibilità, Report ambientale, sociale, risorse umane.

[13] IKEA 2010. Indagine interna Customer Satisfaction Index.

[14] IKEA 2011. Verso la sostenibilità, Report ambientale, sociale, risorse umane. 
International Journal of Managing Information Technology (IJMIT) Vol.4, No.4, November 2012

[15] ISTAT 2009. Scelte di consumo delle famiglie italiane.

[16] ISTAT 2010. Bilancio demografico nazionale.

[17] ISTAT 2010. Italia in cifre.

[18] Lafratta P. 2004. Strumenti innovativi per lo sviluppo sostenibile. Franco Angeli, Milano.

[19] Majocchi R. 2003. L'Europa e un nuovo modello di sviluppo su scala mondiale, Relazione per gli incontri su "Etica e ambiente", Cerema 20 febbraio.

[20] Martucci I., Schirone D.A., 2011. Sviluppo sostenibile quale strategia d'impresa: il caso IKEA. Rivista Italiana di Economia, Demografia e Statistica, vol. LXV n.3/4.

[21] Meadows D.H., Meadows D.L., Randers J., Behrens W.H.,1972. The Limits to the Growth, New York, Universe Books, trad.it. I Limiti allo Sviluppo, Milano, Mondadori, 1981.

[22] Nespor S. 2009. Il governo dell'ambiente. La politica e il diritto per il progresso sostenibile. Milano: Garzanti.

[23] Porter M. E. e Reihardt F. L., 2007. Un approccio strategico al clima. Harvard Business Review Italia, pp.6-10.

[24] Simon J. L., Kahn H. (eds.), 1984. The resourceful Earth: a response to Global 2000. New York: Blackwell.

[25] Stenebo J. 2009, Ikea, Mito e Realtà. Egea Milano.

[26] Wartick S.L., Cochran P.L. 1985. The evolution of the corporate social performance model. Academy of Management Review, 4, pp. 758-769. 